American Journal of

Health, Medicine and Nursing Practice (AJHMN)

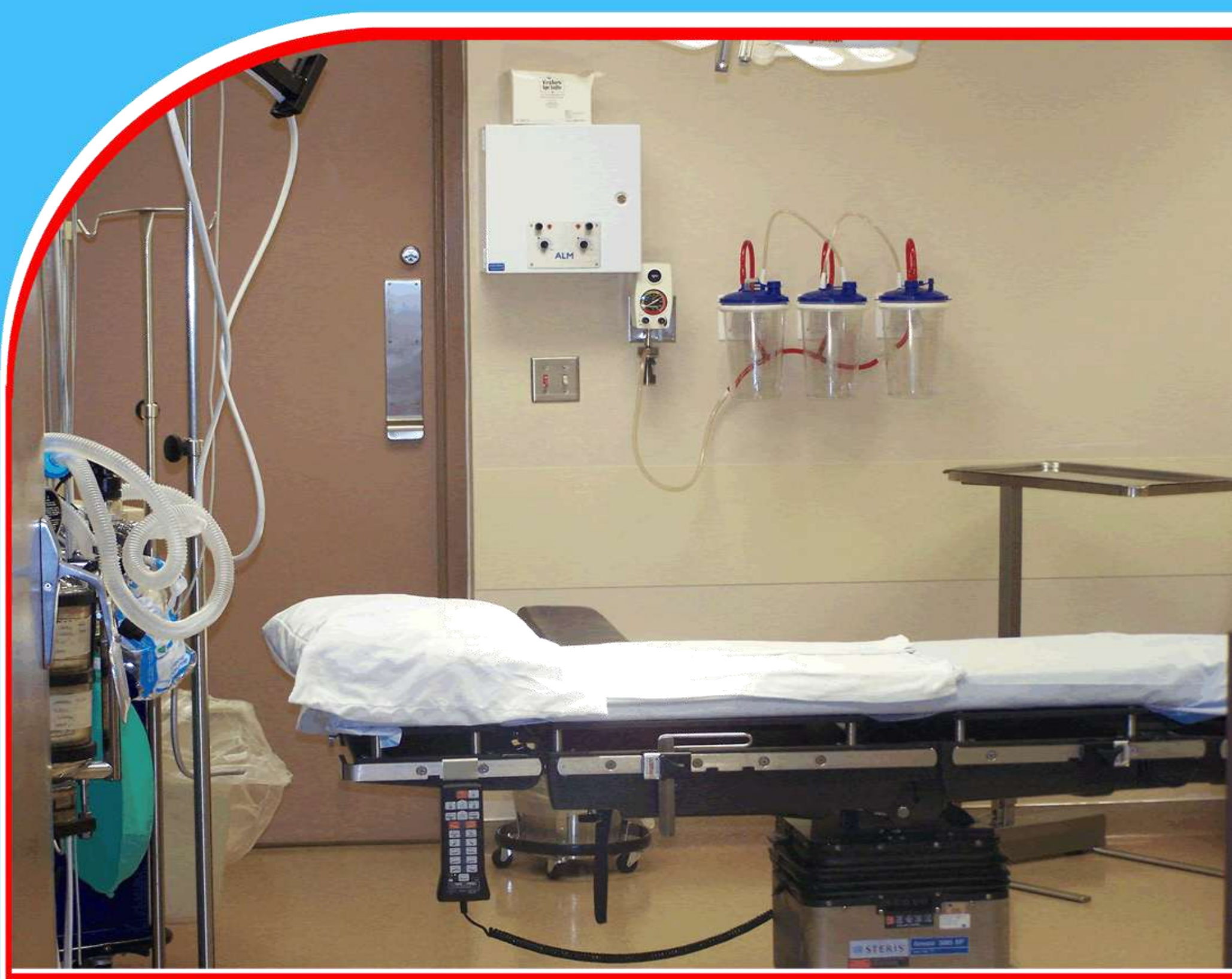

Anticardiolipin antibodies and Lupus anticoagulant; prevalence in pregnant patients with recurrent miscarriages

Fouzia Fahim, Waleed Bin Fahim, Gul Lakhta, Fahad Raja Khan

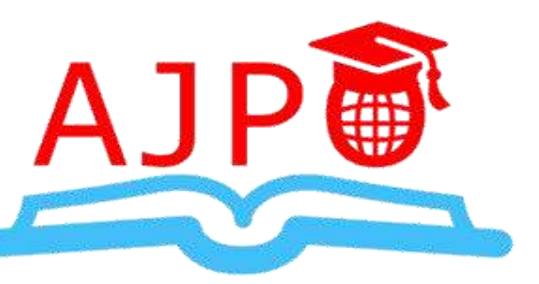




\title{
Anticardiolipin antibodies and Lupus anticoagulant; prevalence in pregnant patients with recurrent miscarriages \\ ${ }^{1 *}$ Fouzia Fahim FCPS, ${ }^{2}$ Waleed Bin Fahim MBBS, ${ }^{3}$ Gul Lakhta MBBS, FCPSII, ${ }^{4}$ Fahad Raja Khan MBBS, FCPSII \\ ${ }^{1}$ Associate Professor of OBGYN, Medical Teaching Institution (MTI), Lady Reading Hospital (LRH), Peshawar, Pakistan. \\ ${ }^{2}$ House Officer, Shifa International Hospital, Islamabad, Pakistan. \\ ${ }^{3,4}$ Trainee Medical Officer, Medical Teaching Institution (MTI), Lady Reading Hospital (LRH), Peshawar, Pakistan \\ *Corresponding Author's Email: fahimazim@gmail.com
}

\begin{abstract}
Objective: Evaluation of the frequency of anticardiolipin antibodies and lupus anticoagulant levels in women with histories of three or more first trimester recurrent miscarriages.

Methodology: It was a descriptive case series carried out at private clinical practice in Peshawar. About 86 patients were enrolled in the study. They had three or more first trimester recurrent abortions. Pregnant patients between ages 22 and 35 years were included. Any patient diagnosed with other etiologies of recurrent miscarriages was excluded. Percentages and frequencies were used to analyze the data.

Results: Mean age of pregnant patients was $28.4( \pm 3.25)$ years. Mean number of miscarriages was 3.5. High anticardiolipin antibodies were detected in $23.3 \%$ of pregnant patients. There was no pronounced difference regarding high levels of $\operatorname{IgG}$ and $\operatorname{IgM}$. No case of raised lupus anticoagulant was found.

Conclusion: Pregnant patients who experience recurrent miscarriages show higher prevalence of antibodies of anticardiolipin type. It is recommended that all such cases should be subjected to APS screening.
\end{abstract}

Keywords: Recurrent miscarriages, antiphospholipid syndrome, anticardiolipin antibodies. Lupus anticoagulant. 
American Journal of Health, Medicine and Nursing Practice

ISSN 2520-4017 (Online)

Vol.7, Issue 3, pp $8-15,2022$

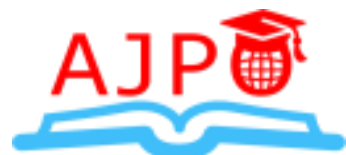

WWW.ajpojournals.org

\section{Introduction}

Recurrent miscarriage is losing three or more consecutive conceptions. It involves one in hundred couples trying to get pregnant. ${ }^{1,2}$ This is considerably higher than anticipated accidently. It indicates that some partners have a continual intrinsic aberration responsible for their conception losses. Common factors that cause recurrent abortions are uterine abnormalities (uterine septum, leiomyomata), cervical conditions (cervical incompetence), chromosomal abnormalities (balanced or Robertsonian translocation, aneuploidy), endocrine disorder (hypothyroidism, poorly controlled diabetes mellitus, polycystic ovarian syndrome), Thrombophilia (factor V leiden), life style factors (smoking, alcohol, drugs), immune factors and antiphospholipid syndrome. ${ }^{3}$ In this context antiphospholipid syndrome (APS) has come out as one of the most significant cause of recurrent abortion which can be successfully treated.

Antiphospholipid syndrome is diagnosed by the presence of antiphospholipid antibodies in pregnant patients who are being investigated for recurrent miscarriages . ${ }^{4}$ Apart from recurrent loss of pregnancies, APS can also lead to other problems as pre-eclampsia, intrauterine fetal growth restriction and placental inadequacy. ${ }^{5-7}$ This syndrome consists of a group of at least 20 auto antibodies aimed to counter the plasma proteins which bound to phospholipids. They are named as antiphospholipid antibodies. The considerably notable form of antibodies are anticardiolipin antibodies (ACA), lupus anticoagulant (LA), and a positive Venereal Disease Research Laboratory test (VDRL). ${ }^{8,9}$

Antiphospholipid antibodies which are considered the most clinically relevant are LA and ACA. About $10-15 \%$ cases of repeated miscarriages have continually positive results for either ACA or LA, in contrast to $0.2-2 \%$ of general obstetrical population. ${ }^{10,11,12}$ Pregnancy loss associated with APS results from thrombosis of utero-placental vasculature, because of binding of antibodies to phospholipids, thus inhibiting the placental anticoagulant proteins. ${ }^{13,14}$ However, thrombosis is not a ubiquitous finding in pregnancies complicated with APS . The main factor that determines the end result of a conception is embedding of the fetus into the decidua followed by trophoblastic incursion followed by placentation. Implantation is an uninterrupted event which begins immediately after fertilization and is mostly completed by the gestational period of twenty weeks. In vitro studies have shown that APS influences the trophoblastic distinction, incursion and function. ${ }^{15,16,17}$

The rate of fetal loss can be reduced by treatment using aspirin, heparin or intravenous immunoglobulins. The benefit of prophylactic management with heparin and aspirin is around $70 \%$. 50\% patients who are not treated have risk of developing pre-eclampsia and placental insufficiency. ${ }^{5}$ Prevention of these pathologies with normalization of ACA is associated with an improvement in live birth rates. ${ }^{18}$ This study was aimed to evaluate the prevalence of high Anticardiolipin antibodies and Lupus anticoagulant titers in patients having recurrent miscarriages in our local population.

\section{Methodology}

It was a descriptive research project. It was validated by the Institutional review board and Committee of ethics, Medical Teaching Institute, Lady Reading Hospital, Peshawar. A total number of 86 consecutive pregnant women with three or more recurrent miscarriages were 
evaluated using non probability sampling technique. It was carried out at private clinical practice at Dabgari Gardens Peshawar Pakistan from November 2016 to January 2017. All the women with three or more consecutive miscarriages in the age group of 22-35 years were selected. In all patients, history and comprehensive physical examination was done. Any patient with uterine abnormalities, endocrine disorders, systemic diseases as diabetes mellitus, thyroid dysfunction, hypertension, Rh incompatibility were not included in the study. Assessment of ACA was done by LIAISON (Diasoun) immunodiagnostic system using chemiluminesence technology. Lupusanticoagulant was evaluevaluby activated partial thromboplastin time (APTT) prolonged by the presence of an inhibitor. Percentages and frequencies were used.

\section{Results}

Mean maternal age was $28.4 \pm 3.25$ years. Maximum number of patients fell in the age group of the years 26-30 (41.86\%). Three recurrent miscarriages were commonest. Mean number of miscarriages was 3.5. A total of $74(86.05 \%)$ patients had three miscarriages. Only two patients had five consecutive miscarriages. (Table 1)

Table 1: Age and Miscarriage Distribution

\section{n $\%$}

Age

$22-25$

20

23.26

26-30

36

41.86

$31-35$

30

34.88

\section{Consecutive Miscarriages}

4

5

Note. Due to rounding errors, percentages may not equal $100 \%$.

ACA levels were raised in $23.3 \%(n=20)$ of women, whereas no case of raised lupus anticoagulant was found. High levels of ACA IgM were detected in $80 \%$ of the cases having positive Anticardiolipin antibodies, whereas ACA IgG were positive in $70 \%$ and elevated levels of both $\operatorname{IgM}$ and $\operatorname{IgG}$ were found in $70 \%$. The number of patients having both high $\operatorname{IgG}$ and $\operatorname{IgM}$ Antibodies did not show any statistically significant difference. (Table 2) 
American Journal of Health, Medicine and Nursing Practice

ISSN 2520-4017 (Online)

Vol.7, Issue 3, pp $8-15,2022$

www.ajpojournals.org

\section{Table 2: Frequency of Antiphospholipid Antibodies}

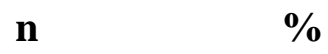

\section{ACA}

Yes

20

23.26

No

66

76.74

IgG

Yes

14

16.28

No

72

83.72

IgM

Yes

16

18.60

No

70

81.40

\section{IgG and IgM}

Yes

14

16.28

No

72

LA

Yes

0

0.00

No

86

100.00

Frequencies and percentages were calculated for Age split by consecutive miscarriages. In the age range of 22-25 years, all the patients (100\%) had three consecutive miscarriages, whereas $89 \%$ of patients in the age range of 26-30 years had three consecutive miscarriages. (Table 3 )

Table 3: Comparison of Consecutive Miscarriages with Age

\begin{tabular}{lrrrr}
\hline & \multicolumn{2}{c}{ Consecutive Miscarriages } & Total \\
\hline Age & $\mathbf{3}$ & $\mathbf{4}$ & $\mathbf{5}$ & \\
$22-25$ & $20(100 \%)$ & $0(0 \%)$ & $0(0 \%)$ & $20(100 \%)$ \\
$26-30$ & $32(89 \%)$ & $2(6 \%)$ & $2(6 \%)$ & $36(100 \%)$ \\
$31-35$ & $22(73 \%)$ & $8(27 \%)$ & $0(0 \%)$ & $30(100 \%)$ \\
\hline
\end{tabular}


American Journal of Health, Medicine and Nursing Practice

ISSN 2520-4017 (Online)

Vol.7, Issue 3, pp $8-15,2022$

www.ajpojournals.org

Frequencies and percentages were calculated for ACA and LA split by consecutive miscarriages. Positive Anticardiolipin antibodies were present in patients with 3 and 4 consecutive miscarriages. None of the patients having 5 consecutive miscarriages had positive antibody titres. (Table 4).

Table 4: Comparison of Consecutive Miscarriages with APS Antibodies

\begin{tabular}{|c|c|c|c|c|}
\hline & \multicolumn{3}{|c|}{ Consecutive Miscarriages } & \multirow[t]{2}{*}{ Total } \\
\hline & 3 & 4 & 5 & \\
\hline \multicolumn{5}{|l|}{$\mathbf{A C A}$} \\
\hline Yes & $18(90 \%)$ & $2(10 \%)$ & $0(0 \%)$ & $20(100 \%)$ \\
\hline No & $56(85 \%)$ & $8(12 \%)$ & $2(3 \%)$ & $66(100 \%)$ \\
\hline \multicolumn{5}{|l|}{ IgG } \\
\hline Yes & $12(86 \%)$ & $2(14 \%)$ & $0(0 \%)$ & $14(100 \%)$ \\
\hline No & $62(86 \%)$ & $8(11 \%)$ & $2(3 \%)$ & $72(100 \%)$ \\
\hline \multicolumn{5}{|l|}{ IgM } \\
\hline Yes & $14(88 \%)$ & $2(12 \%)$ & $0(0 \%)$ & $16(100 \%)$ \\
\hline No & $60(86 \%)$ & $8(11 \%)$ & $2(3 \%)$ & $70(100 \%)$ \\
\hline \multicolumn{5}{|c|}{ IgG and IgM } \\
\hline Yes & $12(86 \%)$ & $2(14 \%)$ & $0(0 \%)$ & $14(100 \%)$ \\
\hline No & $62(86 \%)$ & $8(11 \%)$ & $2(3 \%)$ & $72(100 \%)$ \\
\hline \multicolumn{5}{|l|}{ LA } \\
\hline No & $74(86 \%)$ & $10(12 \%)$ & $2(2 \%)$ & $86(100 \%)$ \\
\hline
\end{tabular}

Note. Due to rounding error, percentages may not sum to $100 \%$.

\section{No of Consecutive Miscarriages}

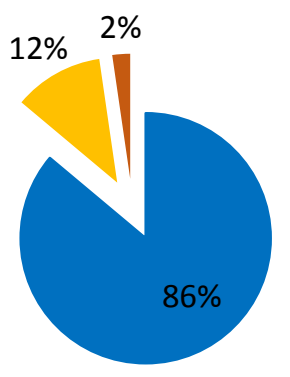

Figure 1: No of Consecutive Miscarriages 


\section{Discussion}

This study detected a prevalence rate of $23.3 \%$ of ACA in pregnant women who suffered from repeated miscarriages. However, no patient was found to have a positive LA antibody. Most of the studies have cited a similar range of high levels of these antibodies. Various publications have reported a prevalence of 11-59\%.,22,26 This wide variation could be because of varied methods used to quantify the antibodies and so a more specific standardization techniques need to be explored. $^{22}$ It has been agreed by various consensus groups that ACA and LA are the foremost distinguished antibodies related intimately with recurrent loss of pregnancies.$^{2}$ In this research study, although higher levels of ACA were detected, but not a single case of LA was found. A study carried out in Brazil ${ }^{4}$ also found only $2 \%$ positive LA antibodies as compared to $55.77 \%$ ACA antibodies. Irrespective of the type of antibody detected, APS has now been identified as one of the treatable causes of recurrent miscarriages.

Recurrent miscarriage is a condition associated with varied etiologies. However, in spite of thorough investigations involving various clinical protocols, the underlying etiology remains obscure in majority of patients. ${ }^{19}$ Lately APS is implicated in various pathologies in obstetrical patients. Arterial and venous thrombosis both are reported. Antiphospholipid syndrome is also associated with infertility and pregnancy complications. In addition to recurrent miscarriages, premature births and still births can also occur. ${ }^{20} \mathrm{High}$ ACA levels have detrimental effects a normal progression of early as well as late pregnancy. Early detection and treatment can prevent recurrent pregnancy losses and improve the outcome of pregnancy. 5,21

One must be aware of the fact that other maternal complications can also occur in positive APS cases. This syndrome is associated with thromboembolic events and clinicians should be aware of this possibility. Overall, the general censuses supports the association between the first trimester loses, adverse perinatal outcomes and positive antiphospholipid antibodies. ${ }^{22,27}$ So it is recommended that every patient with a previous history of recurrent miscarriages should be screened for these antibodies.

\section{Conclusion}

In conclusion, repeated miscarriages are caused by antiphospholipid antibody syndrome in a significant population. These patients should undergo systemic investigation of these antibodies.

\section{Recommendations}

All the patients of recurrent miscarriages should be subjected to APS screening while investigating the causes of recurrent miscarriages.

\section{References}

1. Ogasawara MS, Ozaki Y, Suze originally N. Management of recurrent miscarriages. J obstet and gynecologist Research 2014;40(5):1174-1179.

2. Jameil NA, Tyagi P, Shenefy AA. Incidence of cardiolipin antibodies and lupus anticoagulant factor among women experiencing unexplained recurrent abortion and intrauterine fetal death. Int J Vlin Exp. Pathol 2015; 8(3): 3204-3209. 
American Journal of Health, Medicine and Nursing Practice ISSN 2520-4017 (Online)

Vol.7, Issue 3, pp $8-15,2022$

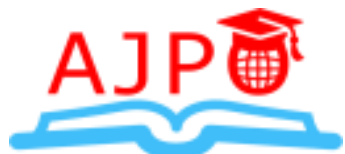

WWW.ajpojournals.org

3. Bhasker N, Kar M, Kumar D. Estimation of antiphospholipid antibodies, anticardiolipin antibodies, beta- 2 glycoprotein 1 antibodies in recurrent pregnancy loss - a case control study. Journal of Clinical and Diagnostic Research 2018 Oct, Vol-12(10).

4. Spegiorin LSJF, Galalo EA, Bagarelli LB, Oilani AH, Godoy JMPd. Prevalence of anticardiolipin antibodies in pregnancies with history of repeated miscarriages. The open Rheumatology Journal 2010: 4; 28-30.

5. Ahlam A, Al Ghamidi,Sawson FM. Etiology of recurrent pregnancy loss in Saudi Females. Saudi J Med sci. 2016 sept-dec ;4(3): 187-191.

6. Ali ST, Shaikhomar O. Anticardiolipin antibodies as diagnostic tool for recurrent spontaneous abortion in Saudi women. Br J Med Health Res. 2020; 7(04).

7. De Godoy Jm, de Godoy MF, Braile DM, Torres CA. Prevalence of anticardiolipin antibodies in peripheral arterial thrombosis. Angiology 2000;5(16): 473-7.

8. Verabelly $\mathrm{M}$ et al. association of recurrent pregnancy loss and anticardiolipin antibodies: prevalence and prognosis of subsequent pregnancy in women with recurrent pregnancy loss. Int J ReprodContraceptObstet Gynecol. 2018 Jan: 7(1): 74-79.

9. Verbally, Malathi, Swapnarani S. Association of recurrent pregnancy loss and anticardiolipin antibodies: prevalence and prognosis of subsequent pregnancy in women with recurrent pregnancy loss. Int $\mathbf{J}$ of reproduction, contraception, obstetrics and Gynaecology 2018;7(1):74.

10. Unlu O, Zuily S, Ervan D. The clinical significance of antiphospholipid antibodies in systemic lupus erythematosus. Eur J Rheumatol 2016 june;3(2):75-84.

11. Cowchock $\mathrm{S}$. The role of antiphospholipid antibodies in obstetrics medicine. CurrObstet Med 1991; 1:229-47.

12. Chaturvedi S, Brodsworth RA, Michael KR. Complement in the Pathophysiology of the antiphospholipid syndrome. Front. Immunol. March2019;| https://doing.org/10.3389/ f immu .2019.00449.

13. Taylor E, Bedaiwy M, Lwes M. Recurrent miscarriage management of pregnancy loss includes investigating causes, addressing modifiable risk factors and providing supportive care in the first trimester of pregnancy. BC Medical Journal 2018;60(5).

14. Out HJ, Kooijman CD, Bruinse HW, Derksen RH. Histopathological findings in placentae from patient with intrauterine fetal death and antiphospholipid antibodies, Eur J ObstetGynoecolRepordBiol 1991; 41: 179-86.

15. Mittal N. Byard R.W. and Dahlstorm J.E. A practical guide to placental examination for forensic pathologists. Forensic sci Med Pathol 2020; 16:295-312.

16. Al-Hilli NM, Al-Mosawi HM. The prevalence of anticardiolipin antibodies in women with bad obstetric history. Al-Qadisiyah Medical Journal 2016;12(21).

17. Salazar-Parmo M, Tara LJ, Ramos A, Barile L, Machador. Garcia - De La Torre I. Longitudual study of antinuclear and anticardiolipin antibodies in pregnant women with SLE and APS. RheumatdInt 2002; 22(4): 142-7.

18. YuviencoC.,Batra K.(2015) The Care and Management of Rheumatologic Diseae in Pregnancy. In :Rosene- montpellier K. (eds) Medical Management of Pregnant patient. Springer, Newyork, NY. https://doing.org/10.1007/978-1-4614-12441_13

19. Farooq N, Akhtar AN, Lodhi Y. Frequency of lupus anticoagulant antibodies in women with recurrent fetal loss. PJMHS Vol.12, No.3, Jul-Sep 2018. 
20. Betz RF,.Speaker C. Pregnancy in Systemic lupus erythematosus and antiphospholipid syndrome. Best practice and Research Clinical Rheumatology 2017; 31(3):397-414

21. AAbdullaiZG,. Abdul MA,.Jibril EM,. Antiphospholipid Antibodies among pregnant women with recurrent fetal wastage in a tertiary hospital in Northern Nigeria. Ann Afr Med.2016 jul-sept;15(3):133-137.

22. Cervera R, Balasch J. Bidirectional effects on autoimmunity and reproduction. Hum Reprod Update 2008; 14: 359-66.

23. Assist.Prof.Hussein N.Abdullah,Y.M.J.,P.D.A.J.H. The Relationship between some immunological criteria and women with recurrent miscarriages. Annals of the Romanian society of cell biology 2021;25(6):69866993.

24. Galli M, Bardui T. Antiphospholipid antibodies and pregnancy Best Pract Res ClinHaematol 2003; 16(2): 211-25.

25. Nafaz Fisal Shakir Agha. Auto antibodies in pregnancy wastage:perspective and challenges. IJMS 2021;6(1):2542-2766.

26. E.Yagmur,E. Bast, A.S. Muhlfeld, A. Koch, R.Weiskirchen,F. Take, J.Neulen. High prevalence of sticky platelet syndrome in patients with infertility and pregnancy loss. J. Clin. Med.2019;8(9):1328. 